\title{
Oral Mucositis Severity Assessment by Supplementation of High Dose Ascorbic Acid During Chemo and/or Radiotherapy of Oro-Pharyngeal Cancers - A Pilot Project
}

\author{
Nallan CSK Chaitanya ${ }^{1 *}$, Arvind Muthukrishnan², Kovur Purushotham Rao ${ }^{3}$, Danam Reshma \\ Priyanka $^{4}$, Polepeddi Ujwala ${ }^{4}$, Hari Abhijeeth ${ }^{4}$, Ajaykartik Kovur ${ }^{4}$, Athmakoor Nikhil Kumar ${ }^{5}$ \\ ${ }^{1}$ Research Scholar, Saveetha Univeristy, Thandalam, Chennai, INDIA. \\ ${ }^{2}$ Department of Oral Medicine and Radiology, Saveetha Dental College, Saveetha University, Chennai, INDIA. \\ ${ }^{3}$ Department of pharmacy, HKE's Society of Pharmacy College, Gulbarga, INDIA. \\ ${ }^{4}$ Department of Oral Medicine and Radiolog, Panineeya Mahavidyalaya Institute of Dental Sciences and Research Centre, Kamala \\ Nagar Road Number- 5, Chaitanyapuri, Dilsukhnagar, Hyderabad, INDIA. \\ ${ }^{5}$ Department of Radiation Oncology, MNJ Institute of Oncology and Regional Cancer Center, Redhills, Hyderabad, INDIA.
}

\begin{abstract}
Introduction: Prevention or control of oral mucositis during cancer therapy can lead to better treatment outcome. The present study was aimed to evaluate the effect of high dose oral ascorbic acid on severity of oral mucositis induced during treatment period. Methods: After informed consent, patients of both the gender with age 18-70 years, were divided into: Group $A(n=19)$ served as controls with no intervention, Group B $(n=20)$ undergoing chemo-radiotherapy and Group $C(n=20)$ receiving conventional radiotherapy. Subjects in group $B$ and group $C$ received varying oral doses of vitamin $\mathrm{C}(2,3$ and $4 \mathrm{~g})$. The therapy initiated $48 \mathrm{~h}$ before the onset of cancer treatment. Intensity of oral mucositis was analysed on day $0,7,14,21,28$ and 35, using WHO grading of oral mucositis by a radiation oncologist. Results: One-Way ANOVA revealed only mild mucositis in experimental group $B$ and $C$ when compared to group $A$ (control) and significant reduction in mucositis in-group $\mathrm{B}$ and $\mathrm{C}$ with $2 \mathrm{~g}$ and $4 \mathrm{~g}$. WHO grade 4 mucositis were less reported in ascorbic acid supplementation groups. Radiotherapy group (Mean SD $3.2+1.64$ ) performed better than the chemo-radiotherapy group (Mean SD $3.7+1.38$ ). Over all, those receiving $4 \mathrm{gm}$ (mean SD 1.3) had shown significantly better scores than those with $2 \mathrm{~g}$ (mean SD 3.38) and $3 \mathrm{~g}$ (mean SD 4.19). Conclusion: The study showed that oral ascorbic acid during radiotherapy and chemo-radiotherapy could alleviate the severity of oral mucositis in patients with cancers.
\end{abstract}

Key words: Ascorbic acid, Mucositis, Grading of mucositis, Radiotherapy, Chemotherapy.

\section{INTRODUCTION}

Oral mucositis is a predictable representation during the treatment of head and neck cancers. The term oral mucositis, depicts inflammation of the oral mucosa invariably independent of lesions with various other pathogenic squeal, commonly called stomatitis. ${ }^{1,2,3}$ The entire gastrointestinal epithelium along with oral cavity, is affected by radiotherapy or chemo radiotherapy induced mucositis. The incidence and severity is directly proportional to the dose, nature and frequency of treatment employed coupled with host factors. The result of radiation mucositis is by free radical release upon irradiation and direct tissue injury arising from DNA damage. ${ }^{4,5,6}$ This usually results in stomatodynia, dysphagia, changes in taste perception and xerostomia. Secondary bacterial, viral and fungal infections form another spectrum of the mucositis associated illness. ${ }^{4,5,7}$
Submission Date: 11-10-2017; Revision Date: 21-11-2017; Accepted Date: 19-12-2017

DOI: 10.5530/ijper.52.3.61 Correspondence: Nallan CSK Chaitanya, Research Scholar of Saveetha University, Thandalam, Chennai.

Phone: 918374930914 E-mail: nallanchaitanya@ gmail.com

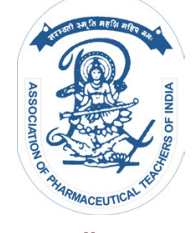

www.ijper.org 
Chemotherapy during cancer treatment has pronounced effect on DNA synthesis and effects THE cells during the $S$ phase of cell cycle. The agents commonly employed are cisplatin, carboplatin, 5-fluoro- uracil and methotrexate for oro-pharyngeal cancers. Large bolus and continuous infusions of these agents have shown marked adverse effects particularly inducing rapid mucositis. The incidence of such occurrence is about $76 \%$ in chemotherapy and approximately $30-60 \%$ in radiotherapy employed individuals. The incidence raises to about $88-90 \%$ when concurrent chemo-radiotherapy is given as treatment. ${ }^{3-7}$

Antioxidants in the form of vitamin supplements may be selective radiation modifying agents that do not show much adverse effects but exert their influence selectively on cancer cells. Despite reservations on their usage during treatment, about $70 \%$ of patients consume micronutrients containing various FDA approved doses of vitamin $A$, vitamin $C$ and polar carotenoids under the supervision of oncologists and sometimes over the counter. ${ }^{7-11}$

Exhaustive literature survey listed many antioxidants, such as beta-carotene, vitamin $\mathrm{E}$ and vitamin $\mathrm{C}$ in combination, glutamine, lysofylline, selenium, glutathione that were employed with variable degree of success in prevention or treatment of oral mucositis. Only zinc supplements were favored and suggested for oral mucositis till date according to guidelines of MASCC/ ISOO. (Vitamin C, a water-soluble nutrient, has shown wide antioxidant and wound healing capacity. It has been widely used in scurvy patients but its potential use during conventional chemo-radiation and its cumulative effects were little known. Limited invitro data suggested that when this vitamin was used at high concentrations, the efficacy of certain chemotherapeutic agents increased in animal models. ${ }^{12}$

Recommended daily allowance ( RDA) for Ascorbic acid is $90 \mathrm{mg}$ per day for men and $75 \mathrm{mg}$ per day for women, upper limit is set at $4 \mathrm{~g}$ per day. It has been suggested that the intake to achieve therapeutic tissue concentration in normal people should be several times higher than RDA., ${ }^{4,10,12}$ Vitamin c (ascorbic acid) of $500 \mathrm{mg}$ twice daily regime is the drug for scurvy. Considering the wound healing and collagen formation properties of the vitamin for oral mucositis, this study was undertaken to possibly demonstrate the effect of oral ascorbic acid from $2 \mathrm{~g}$ to $4 \mathrm{~g}$ daily dose during chemo-radiotherapy. Our primary aim and objective was to assess the severity of oral mucositis during chemo-radiotherapy for oral cancer. In addition, to compare the effect of oral vitamin $\mathrm{C}, 2 \mathrm{~g}, 3 \mathrm{~g}$ and $4 \mathrm{~g}$ at increasing dosages oral supplementation during chemo-radiotherapy induced oral mucositis with suitable controls.

\section{MATERIALS AND METHODS}

A pilot study was initially conducted on a small group by increasing concentrations of vitamin c orally in non-chewable form from $500 \mathrm{mg}$ until perceivable clinical benefit of reduced oral mucositis was noted. The sample revealed that there was no effect of the vitamin with doses of $500 \mathrm{mg}$ till $2 \mathrm{~g}$ on oral mucositis. This standpoint marked the commencement of the present study employing $2 \mathrm{~g}, 3 \mathrm{~g}$ and $4 \mathrm{~g}$ of oral ascorbic acid and assessed for changes in the severity of oral mucositis during cancer- chemo and/or radiotherapy. WHO clinical grading of oral mucositis was used after obtaining informed consent. The present study was a randomized controlled trial undertaken in $\mathrm{MNJ}$ institute of oncology and regional cancer center after obtaining the ethical clearance bearing number: ECR/227/ INSP/AP/2014 and clinical trial registry number: NCT02868151. The pilot study period was for a period of 8 months.

The patients of either gender with age group between 18 to 70 years were recruited from the respective center after obtaining written consent from department of radiation oncology undergoing Chemo and/or radiotherapy of oral and oro-pharyngeal cancers using a random stratified sampling method by computer generated sample score. The patients were not blinded about the intervention and they were allowed free will to choose which intervention they would prefer. The sample size was determined based on the prevalence of oral mucositis in the region and attending hospital. Total numbers of 59 patients were included in the study. The patients were assigned into 3 different groups i.e. Group A and Group B and Group C.

1. Group A patients $(n=19)$ served as control arm in whom standard protocol for oral mucositis treatment was being implemented in the cancer hospital with no intervention from the investigator.

2. Group B patients $(\mathrm{n}=20)$ undergoing chemo-radiotherapy with weekly once cisplatin 50mg and standard conventional radiation dose between 44-66 Gy were divided into 3 subsets: $2 \mathrm{~g}$ of ascorbic acid intervention, $3 \mathrm{~g}$ of ascorbic acid intervention and $4-\mathrm{g}$ intervention subsets. The therapy commenced $48 \mathrm{~h}$ before the initiation of radiotherapy and continued for the entire treatment. After the cessation of cancer treatment, the dose of vitamin $\mathrm{C}$ was reduced to half of its initial dose over a 4-week period and was gradually stopped. The total period of vitamin therapy was 2 months. The regular standard treatment continued without cessation during entire trial. 
3. Group $\mathrm{C}$ patients $(\mathrm{n}=20)$ receiving only conventional radiotherapy between 44-66 Gy for various oral and oro-pharyngeal cancers were again divided into three small subsets having intervention of $2 \mathrm{~g}$, $3 \mathrm{~g}$ and $4 \mathrm{~g}$ of ascorbic acid orally. The therapy was initiated similar to chemo-radio therapy group and followed up till 4-week period post cessation of therapy with tapering dose. The radiotherapy dose was calculated for each carcinoma individually and a hyper fractionated dose was given at 2 cGy per day, five days a week for a total dose of 44-66 Gy.

Subjects in all the groups were monitored for oral mucositis as per WHO grading from the day of initiation of treatment until the treatment cessation. ${ }^{13}$

Grade $0=$ No oral mucositis, Grade $1=$ Erythema and Soreness, Grade 2 = Ulcers, able to eat solids, Grade 3 $=$ Ulcers, requires liquid diet (due to mucositis), Grade 4 = Ulcers, alimentation not possible (due to mucositis) The Exclusion criteria were patients with known allergy to vitamin C, with G6PD deficiency and those with renal failure. All patients were evaluated biochemically and hematologically for renal functions at every week. Any adverse effects with the high dose of vitamin c were noted down and evaluated if any emergency basis. All patients were at liberty to withdraw from the study at any given point of time. Data was analyzed using Microsoft excel and SPSS version 20.0 software. Demographic characteristics of the patients, tumors, radiation dosage were compared between the groups. To assess the severity or intensity of oral mucositis, one-way ANOVA was used. Then, further to compare the groups, Mann-Whitney U test was used. All the statistical tests were two-tailed with level of significance set at $5 \%$.

\section{RESULTS}

Originally, 59 patients were selected for investigation and as study progressed, 1 from group $A$ and 1 from group B were excluded from the study when it is half way through because of death of the individuals. Consequently, there were 18 patients in Group A, 19 in Group B and 20 in Group C, where the latter groups were provided with vitamin $C$ supplementations. (Table 1, Table 2, Table 3)

At the beginning of this trial, none of the patients had shown symptoms of oral mucositis. By $7^{\text {th }}$ day the intensity of oral mucositis, increased to 2.2 (mean of mucositis severity score) in those who were receiving $2 \mathrm{gm} /$ day of vitamin $\mathrm{C}$ supplementation, whereas this intensity increased up to 2.7 in those receiving $3 \mathrm{gm} /$ day and then with increased dosage up to $4 \mathrm{gm} /$ day, the severity decreased to 1.7. There was statistically significant difference $(p<0.05)$ was found in mucositis intensity on day 7, 21, 28 and 35 among those receiving different doses of vitamin $\mathrm{C}$, except on day 14 which was not significant ( $\mathrm{p}>0.05)$ (Table. 4).

When severity of mucosa was compared among patients from different groups, statistically significant difference was found between the groups only on day 14 and 21, with $\mathrm{p}$ value $<0.05$, and no difference was observed between groups on day 7, 28 and $35(p=0.404$; 0.704; 0.275) (Table 5). When severity of mucositis was assessed, milder mucositis was observed in experimental groups i.e. group $\mathrm{B}$ and $\mathrm{C}$ when compared to group $\mathrm{A}$ (controls) which had shown severe mucositis. When severity of mucositis was assessed in terms of vitamin C supplementation i.e. dosage levels, patients those receiving $2 \mathrm{gm} /$ day had shown mucositis mean intensity of 1.47 , patients receiving $3 \mathrm{gm} /$ day had shown 1.64 and those receiving $4 \mathrm{gm} /$ day showed mean intensity of 1.33. There were significant differences found $(p<0.05)$ among the dosage levels which means with increase in dose, there is decrease in severity of oral mucositis (Table 6).

\section{DISCUSSION}

Oral cavity lining is complex and can be considered susceptible target for treatment related toxicity. It is highly susceptible to direct and indirect toxic effects of ionizing radiation and chemotherapy and elements of oral microbial environment. ${ }^{14,15,16,17}$. Oral mucositis is a common, debilitating complication that occurs in about

\begin{tabular}{|c|c|c|c|}
\hline Characteristics & $\begin{array}{l}\text { Case group } \\
(n=40)\end{array}$ & $\begin{array}{c}\text { Control group } \\
(n=19)\end{array}$ & $p$ \\
\hline \multicolumn{4}{|l|}{ Gender } \\
\hline Male & $31(77.5)$ & $13(68.4)$ & 0.61 \\
\hline Female & $9(22.5)$ & $6(31.6)$ & 0.89 \\
\hline Age in Years & 52.05 & 55.94 & 0.27 \\
\hline
\end{tabular}

Values are $n(\%)$

Table 2: Characteristics of different treatment modalities in the pilot study.

\begin{tabular}{|c|c|c|c|}
\hline Characteristics & $\begin{array}{c}\text { Case group } \\
(\mathbf{n = 4 0 )}\end{array}$ & $\begin{array}{c}\text { Control } \\
\text { group } \\
(\mathbf{n = 1 9 )}\end{array}$ & $\mathbf{p}$ \\
\hline \multicolumn{4}{|l|}{} \\
\hline Treatment \\
\hline Chemoradiotherapy & $20(50)$ & $10(52.6)$ & 0.32 \\
\hline Radiotherapy & $20(50)$ & $9(47.4)$ & 0.57 \\
\hline Chemotherapy & $0(0)$ & $0(0)$ & \\
\hline
\end{tabular}




\section{Table 3: Characteristics of Patient tumor presentation between case and control group}

\begin{tabular}{|c|c|c|c|}
\hline \multicolumn{2}{|c|}{ Characteristics } & $\begin{array}{c}\text { Case group } \\
(\mathbf{n = 4 0 )}\end{array}$ & Control group (n=19) \\
\hline Classification of cancer & \multirow{2}{*}{0.41} \\
\hline Palate & $2(5)$ & $1(5.2)$ & 0 \\
\hline Lateral border of tongue & $1(2.5)$ & $6(31.6)$ & $1(5.2)$ \\
\hline Buccal mucosa & $16(40)$ & $1(5.2)$ & $2(10.5)$ \\
\hline Oropharynx & $2(5)$ & $5(26.3)$ & 0 \\
\hline Maxilla & 0 & 0 \\
\hline Tonsil & $2(5)$ & $3(15.8)$ \\
\hline Tongue & $11(27.5)$ & 0 \\
\hline Ventral surface of tongue & $1(2.5)$ & $2(5)$ & \\
\hline Parotid Adenoid cystic & $2(5)$ & $1(2.5)$ & \\
\hline Alveolus & &
\end{tabular}

Values of $n(\%)$

\begin{tabular}{|c|c|c|c|c|c|c|c|}
\hline \multirow[b]{2}{*}{ Vit C Suppl. } & \multirow[b]{2}{*}{$\mathrm{n}$} & \multicolumn{6}{|c|}{ Week } \\
\hline & & $\begin{array}{c}\text { Day 0 } \\
(\text { Mean+sd) } \\
95 \% \mathrm{Cl}\end{array}$ & $\begin{array}{c}\text { Day } 7 \\
\text { (Mean+sd) } \\
95 \% \mathrm{Cl}\end{array}$ & $\begin{array}{c}\text { Day } 14 \\
\text { (Mean+sd) } \\
95 \% \mathrm{Cl}\end{array}$ & $\begin{array}{c}\text { Day } 21 \\
(\text { Mean+sd) } \\
95 \% \mathrm{Cl}\end{array}$ & $\begin{array}{c}\text { Day } 28 \\
(\text { Mean+sd) } \\
95 \% \mathrm{Cl}\end{array}$ & $\begin{array}{c}\text { Day } 35 \\
(\text { Mean+sd) } \\
95 \% \mathrm{Cl}\end{array}$ \\
\hline 2gm/day & 15 & $\begin{array}{c}1 \pm 0.00 \\
1.00-1.00\end{array}$ & $\begin{array}{c}2.2 \pm 1.14 \\
1.56-2.83\end{array}$ & $\begin{array}{l}3.1 \pm 0.63 \\
2.77-3.48\end{array}$ & $\begin{array}{l}3.7 \pm 0.76 \\
3.20-4.26\end{array}$ & $\begin{array}{l}4.1 \pm 1.03 \\
3.49-4.63\end{array}$ & $\begin{array}{l}4.1 \pm 1.22 \\
3.38-4.74\end{array}$ \\
\hline 3gm/day & 11 & $\begin{array}{c}1 \pm 0.00 \\
1.00-1.00\end{array}$ & $\begin{array}{l}2.7 \pm 0.46 \\
2.41-3.04 \\
\end{array}$ & $\begin{array}{l}3.1 \pm 0.40 \\
2.91-3.45 \\
\end{array}$ & $\begin{array}{r}4.1 \pm 0.30 \\
3.88-4.29 \\
\end{array}$ & $\begin{array}{c}4.7 \pm 0.46 \\
4.41-5.06 \\
\end{array}$ & $\begin{array}{l}4.5 \pm 0.52 \\
4.19-1.89 \\
\end{array}$ \\
\hline 4gm/day & 14 & $\begin{array}{c}1 \pm 0.00 \\
1.00-1.00\end{array}$ & $\begin{array}{l}1.7 \pm 0.91 \\
1.18-2.24\end{array}$ & $\begin{array}{l}2.9 \pm 0.82 \\
2.45-3.40\end{array}$ & $\begin{array}{l}2.7 \pm 0.99 \\
2.14-3.28\end{array}$ & $\begin{array}{l}2.4 \pm 0.85 \\
1.93-2.92\end{array}$ & $\begin{array}{l}1.9 \pm 1.07 \\
1.31-2.54\end{array}$ \\
\hline None & 19 & $\begin{array}{c}1 \pm 0.00 \\
1.00-1.00\end{array}$ & $\begin{array}{l}2.2 \pm 0.45 \\
2.04-2.48\end{array}$ & $\begin{array}{l}3.4 \pm 0.51 \\
3.22-3.72\end{array}$ & $\begin{array}{c}4 \pm 0.57 \\
3.72-4.27\end{array}$ & $\begin{array}{l}3.9 \pm 1.31 \\
3.31-4.57\end{array}$ & $\begin{array}{l}3.9 \pm 1.35 \\
3.29-4.59\end{array}$ \\
\hline$p$-value & 59 & --- & 0.025 & 0.098 & 0.000 & 0.000 & 0.000 \\
\hline
\end{tabular}

\begin{tabular}{|c|c|c|c|c|c|c|c|}
\hline \multirow{2}{*}{ Patient Groups } & \multirow[b]{2}{*}{$\mathbf{n}$} & \multicolumn{6}{|c|}{ Week } \\
\hline & & $\begin{array}{c}\text { Day 0 } \\
\text { (Mean+sd) } \\
95 \% \mathrm{Cl}\end{array}$ & $\begin{array}{c}\text { Day } 7 \\
\text { (Mean+sd) } \\
95 \% \mathrm{Cl}\end{array}$ & $\begin{array}{c}\text { Day } 14 \\
\text { (Mean+sd) } \\
95 \% \mathrm{Cl}\end{array}$ & $\begin{array}{c}\text { Day } 21 \\
\text { (Mean+sd) } \\
95 \% \mathrm{Cl}\end{array}$ & $\begin{array}{c}\text { Day } 28 \\
\text { (Mean+sd) } \\
95 \% \mathrm{Cl}\end{array}$ & $\begin{array}{c}\text { Day } 35 \\
\text { (Mean+sd) } \\
95 \% \mathrm{Cl}\end{array}$ \\
\hline $\begin{array}{l}\text { Chemoradiotherapy } \\
\text { (with vitamin C) }\end{array}$ & 20 & $\begin{array}{c}1 \pm 0.00 \\
1.00-1.00\end{array}$ & $\begin{array}{l}2.3 \pm 1.13 \\
1.81-2.88\end{array}$ & $\begin{array}{l}3.3 \pm 0.65 \\
2.99-3.60\end{array}$ & $\begin{array}{l}3.7 \pm 1.08 \\
3.19-4.20\end{array}$ & $\begin{array}{l}3.7 \pm 1.21 \\
3.18-4.31\end{array}$ & $\begin{array}{l}3.7 \pm 1.38 \\
3.05-4.34\end{array}$ \\
\hline $\begin{array}{l}\text { Radiotherapy } \\
\text { (with vitamin C) }\end{array}$ & 20 & $\begin{array}{c}1 \pm 0.00 \\
1.00-1.00\end{array}$ & $\begin{array}{l}2 \pm 0.79 \\
1.62-2.37\end{array}$ & $\begin{array}{l}2.8 \pm 0.85 \\
2.57-3.12\end{array}$ & $\begin{array}{l}3.2 \pm 0.91 \\
2.82-3.67\end{array}$ & $\begin{array}{l}3.6 \pm 1.35 \\
2.96-4.23\end{array}$ & $\begin{array}{l}3.2 \pm 1.64 \\
2.43-3.96\end{array}$ \\
\hline $\begin{array}{c}\text { Control } \\
\text { (without vitamin C) }\end{array}$ & 19 & $\begin{array}{c}1 \pm 0.00 \\
1.00-1.00\end{array}$ & $\begin{array}{l}2.2 \pm 0.45 \\
2.04-2.48\end{array}$ & $\begin{array}{l}3.4 \pm 0.51 \\
3.22-3.72\end{array}$ & $\begin{array}{l}4 \pm 0.57 \\
3.72-4.27\end{array}$ & $\begin{array}{l}3.9 \pm 1.31 \\
3.31-4.57\end{array}$ & $\begin{array}{l}3.9 \pm 1.35 \\
3.29-4.59\end{array}$ \\
\hline$p$-value & 59 & --- & 0.404 & 0.005 & 0.035 & 0.704 & 0.275 \\
\hline
\end{tabular}




\begin{tabular}{|c|c|c|c|c|c|c|c|}
\hline \multirow{2}{*}{$\begin{array}{c}\text { Vitamin C } \\
\text { Supplementation }\end{array}$} & \multirow{2}{*}{$n$} & \multirow{2}{*}{ Mean } & \multirow{2}{*}{ SD } & \multicolumn{2}{|c|}{$95 \% \mathrm{Cl}$ for Mean } & \multirow{2}{*}{$\mathrm{F}$} & \multirow{2}{*}{$p$-value } \\
\hline & & & & Lower & Upper & & \\
\hline Nil & 19 & 3.00 & 0.00 & 3.00 & 3.00 & \multirow[t]{5}{*}{55.290} & \multirow[t]{5}{*}{$<0.001^{*}$} \\
\hline 2gm/day & 15 & 1.47 & 0.51 & 1.18 & 1.75 & & \\
\hline 3gm/day & 11 & 1.64 & 0.50 & 1.30 & 1.98 & & \\
\hline 4gm/day & 14 & 1.33 & 0.51 & 1.13 & 1.73 & & \\
\hline Total & 59 & 1.98 & 0.82 & 1.77 & 2.20 & & \\
\hline
\end{tabular}

$40 \%$ of patients receiving CRT for cancer treatment. ${ }^{18,19}$ Management of such patients is vital as they may discontinue therapy and invariably ineffective treatment. The effectiveness of various drugs for prevention or treating mucositis was not effective and there is no proper method available in literature for effective prevention and treatment of this sequalae. ${ }^{20,21,22} \mathrm{Lin}$ et al. verified whether zinc supplementation can accelerate healing process in patients undergoing radiotherapy and concluded that it could postpone the development of severe mucositis and dermatitis for patients with head and neck cancers. ${ }^{20}$

Ascorbate (Vitamin C), as an agent in cancer treatment, it has convoluted history. Even though with divided opinions, vitamin $\mathrm{C}$ and its capability for cancer treatment, many had reported improvement in quality of life..$^{23,24}$ Cameron and Campbell, treated patients with variety of advanced cancers with high doses of both oral and i.v. ascorbate and suggested that there is possible survival benefit when vitamin $C$ was supplemented in cancer treatment for patients with advanced cancer. ${ }^{25}$ Jacobs et al. opined that evidence regards ascorbate's supplementation and its role in improvement of quality of life and reduction of toxicity of chemotherapy is not strong enough. They also emphasized the need of welldesigned studies for further exploration in this topic. ${ }^{26}$

The literature search has revealed total of six studies using oral ascorbate among which three were randomized control trials (RCTs), one each were phase II study, observational study and a case report. ${ }^{27-32}$ In RCTs, patients with advanced cancers of all types were included and the dosage of oral ascorbate ranged from $1 \mathrm{gm}$ to $10 \mathrm{gm}$ with mean dose of $6.3 \mathrm{gm} .{ }^{27-31}$ The outcome from these studies reported as overall survival and overall response and safety in one study. ${ }^{30}$ However, neither of these studies reported secondary outcomes of difference regarding quality-of-life or toxicity outcomes in patients. In one study, where ascorbate was used in combination with chemotherapy group has showed greater improvement than just with chemotherapy alone, and also reported change in tumor diameter in combination $^{29}$
Until date, to the best of our knowledge, no studies were carried out about oral ascorbic acid (vitamin C) and its role in the reduction of severity of oral mucositis in patients receiving CRT. This trial was designed to evaluate the effect of vitamin $\mathrm{C}$ administered at different doses (2, 3 and $4 \mathrm{~g}$ ) on oral mucositis thus, possibly explore its role in prevention/treatment of the same during chemo and/or radiotherapy.

Prasad KN et al. have discussed about micronutrient protocol and proposed high doses of dietary antioxidants such as vitamin $\mathrm{c}$ as adjunct to radiotherapy. ${ }^{4}$ Based on human studies, oral supplementation with vitamin $\mathrm{C}$ doses up to $10 \mathrm{~g} /$ day is considered as high dose and have been used in human cancer treatment without toxicity. 28,33

In present study, all patients were informed to take supplements daily at equal doses. In this study, 500mg tablets of vitamin $\mathrm{C}$ were used. In patients receiving $2 \mathrm{gm} /$ day dose (i.e. $4 \times 500 \mathrm{mg}$ ), were informed to take two tablets in morning and remaining one-half dose in evening. Likewise, those receiving $3 \mathrm{gm}$ and $4 \mathrm{gm}$, their rationale was also divided equally. The rationale for taking the micronutrient throughout the day was based on the biological half-life of the vitamin $\mathrm{C}$ tablet i.e. 4- 6 h. This supplementation of vitamin $C$ was started two days prior to initiation of standard therapy and continued for a period of over one month ( $\approx 35$ days). At regular intervals, the extent and severity of oral mucositis was recorded. Grading of mucositis was performed by a trained specialist on day 1 before treatment, and then followed on day 7, 14, 21, 28 and 35. The score was assessed, as per WHO toxicity grading criteria ${ }^{34,35}$ The present study showed that even though oral supplementation did not decrease incidence of oral mucositis, it decreased the intensity of mucositis in patients. When the severity of mucositis was assessed among the groups, it seemed to be milder in those patients receiving radiotherapy, than those receiving chemoradiotherapy, whereas patients from control group not receiving vitamin $\mathrm{C}$ supplementation had shown more severity of mucositis (Graph 1). This decrease in severity of mucositis among groups when compared to controls 
suggests that vitamin $C$ supplementation might decrease mucositis intensity. With respect to radiation mucositis following vitamin C supplementation, our findings showed constant increase in intensity of mucositis till $28^{\text {th }}$ day (Mean score 3.28) and further decrease at end of $35^{\text {th }}$ day (2.88). Results were same for those receiving CRT, with less difference between $28^{\text {th }}$ and $35^{\text {th }}$ day (Graph 1).

In this study, no significant difference was found in the improvement of radiation mucositis, in fact there was increase in intensity of mucositis with mean score of 2.56 when $2 \mathrm{gm} /$ day is given, which then increased to 3.21 in those supplemented with $3 \mathrm{gm} /$ day. But significant difference was observed in radiation mucositis (mean score of 1.91) for those who received $4 \mathrm{gm} /$ day vitamin $C$ supplementation. Similar findings were also observed for patients under CRT with oral supplementation with lesser reduction in oral mucositis compared to control group (Graph 2). The possible reason behind increase in intensity of oral mucositis with increase in dose of vitamin C (2gm to $3 \mathrm{gm} /$ day) is that low doses of individual antioxidants may be confounding factors with variable host defense, microbial invasion that may have contributed to such a finding. With further increase in dosage to $4 \mathrm{gm} /$ day, we observed a significant decrease in intensity of mucositis, which showed the reduction of toxicity on normal cells when compared to lower dosages.

\section{Limitations and Scope for improvement}

Few possible limitations were, in current study serum analysis of vitamin c were not considered due to cost burden and also microbial testing when analyzing the effectiveness of vitamin $\mathrm{C}$ in preventing the oral muco-

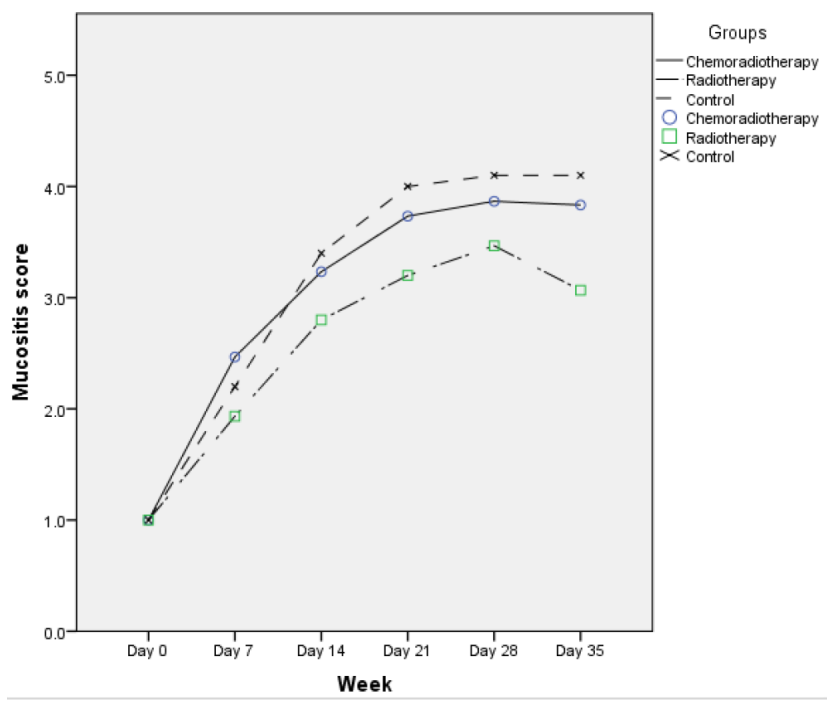

Graph 1: Mean scores for severity of mucositis during treatment period. Symbols represents mean scores

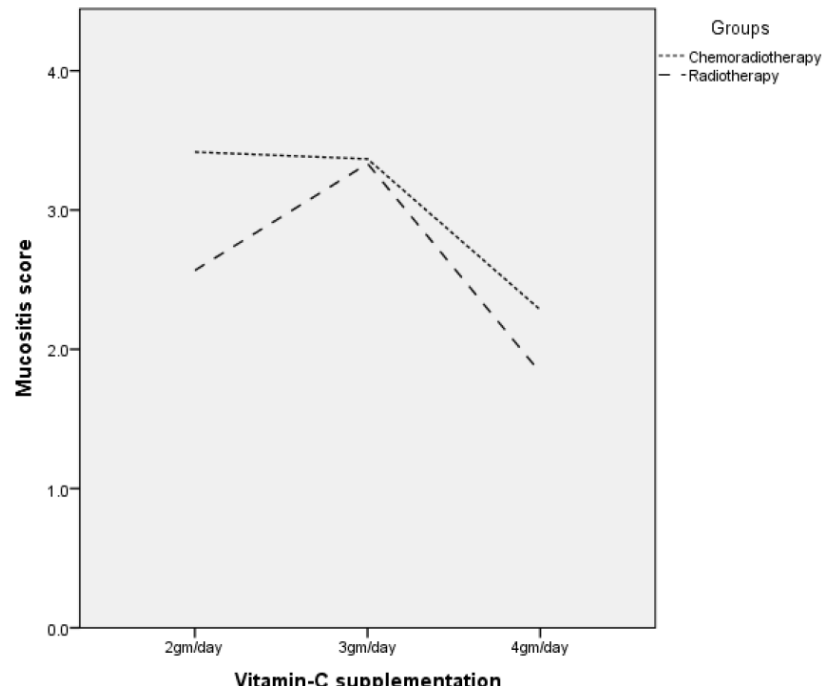

Graph 2: Mean scores for severity of mucositis against Vitamin $\mathrm{C}$ supplementation.

sitis. Furthermore, to test its efficacy it is important to test with recommended criteria laid down by International Academy of Oral Oncology. Moreover, single specialist supervision further highlighting the deficit of testing inter-observer variability performance.

The findings of present trial had shown that use of oral vitamin $\mathrm{C}$ supplementation, particularly when consumed at high concentration i.e. $4 \mathrm{gm} /$ day can significantly decrease in intensity of mucositis in patients who suffer from oro-pharyngeal cancers and are under radiotherapy and CRT. No further side-effects were reported and the administered drug was proved easy and safe to use.

\section{ACKNOWLEDGEMENT}

We acknowledge the teaching and non teaching staff of MNJ institute of oncology and regional cancer center, panineeya institute of dental sciences for their cooperation during the study period. We are thankful to Dr Pradymna and Dr Prakash for their wholehearted support and cooperation for implantation of this project

\section{CONFLICT OF INTEREST}

The authors declare no conflcit of interest.

\section{ABBREVIATIONS}

WHO: World Health Organisation; ANOVA: Analysis of Variance; MASCC/ISOO: Multinational Association of Supportive Care in Cancer/ International Society of Oral Oncology; CRT: Chemo Radiotherapy; Gy: Gray. 


\section{REFERENCES}

1. Köstler WJ, Hejna M, Wenzel C, Cristoph C. Oral mucositis complicating chemotherapy and or radiotherapy- options for prevention and treatment. Cancer J Clin. 2001;51(5):290-315.

2. Edward DR, Dougles EP, Mark S, Dorothy K, Deborah M. Clinical practice guidelines for the prevention and treatment of cancer therapy- induced oral and gastro intestinal mucositis. Cancer. 2004;100(S9):2026-46.

3. Brian DL, Kara M, Elena J, Stephan M, Andrew V. Should supplemental antioxidant administration be avoided during chemotherapy and radiation therapy? J Natl cancer Inst. 2008;100(11):773-83.

4. Prasad KN, Cole WC, Kumar B, Prasad KC. Pros and cons of antioxidant use during radiation therapy. Cancer treatment reviews. 2002;28(2):79-91.

5. Citrin D, Cotrim AP, Fuminori H, Bruce JB, Murali CK, James BM. Radioprotectors and mitigators of radiation- induced normal tissue injury. The oncologist. 2010;15(4):360-71.

6. Ines B, Luis AT, Sheldon M. Management of oral mucositis induced by chemotherapy and radiotherapy. An update. Quintessence Int. 2004;35(2):129-36.

7. Charles BS, Nicole LS, Victoria S. Antioxidants and other nutrients do not interfere with chemotherapy or radiation therapy and can increase kill and increase survival. Alternative therapies. 2007;13(1):22-8.

8. Nechuta S, Lu W, Chen Z. Vitamin supplement use during breast cancer treatment and survival: a prospective cohort study. Cancer epidemiolol biomarkers Prev. 2011;20: 262-71.

9. Ralph WM. Should patients undergoing chemotherapy and radiotherapy be prescribed antioxidants? Integrative cancer therapies. 2006;5(1):63-82.

10. Prasad KN. Rationale for using high dose multiple dietary antioxidants as an adjunct to radiation therapy and chemotherapy. Am Soc Nutri Scien. 2004;134(11):3182-3.

11. Norman HA, Butrum RR, Feldman E, Heber D, Nixon D, Marie FB. The role of dietary supplements during cancer therapy. J nutr. 2003;133(11):3794-9.

12. Cameron E, Pauling L, Brain L. Ascorbic acid and cancer: A review. Cancer res. 1979.39(3):663-81.

13. Lalla RV, Sonis ST, Peterson DE. Management of Oral Mucositis in Patients with Cancer. Dental clinics of North America. 2008;52(1):61-77. doi:10.1016/j. cden.2007.10.002

14. Epstein JB, Thariat J, Bensadoun RJ, Barasch A, Murphy BA, Kolnick L, et al. Oral complications of cancer and cancer therapy: from cancer treatment to survivorship. CA Cancer J Clin. 2012;62(6):400-22.

15. Oral Complications of Chemotherapy and Head/Neck Radiation (PDQ)Health Professional Version. National Cancer Institute. Available from https:// www.cancer.gov/about-cancer/treatment/side-effects/mouth-throat/oralcomplications-hp-pdq

16. Lalla RV, Brennan MT, Schubert MM: Oral complications of cancer therapy. In: Yagiela JA, Dowd FJ, Johnson BS, et al., eds.: Pharmacology and Therapeutics for Dentistry. 2011. 6th ed. St. Louis, Mo: Mosby Elsevier, pp 782-98

17. Kwong KK. Prevention and treatment of oropharyngeal mucositis following cancer therapy: are there new approaches? Cancer Nurs. 2004;27(3):183-205.

\section{PICTORIAL ABSTRACT}

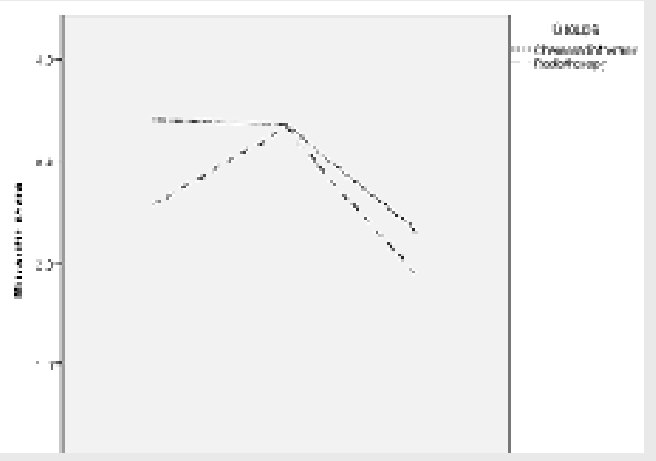

Reduction in severity of mucositis against high dose oral Vitamin $\mathrm{C}$ supplementation..
18. Prevention and Treatment of Oral Mucositis in Cancer Patients. Evidence Based Practice Information Sheets for Health Professionals. Best Practice. 1998;2(3);1-6.

19. Jones DL, Rankin KV. Management of the oral sequelae of cancer therapy. Text den j. 2012;129(5):461-8.

20. Lin LC, Que J, Lin LK, Lin FC. Zinc supplementation to improve mucositis and dermatitis in patients after radiotherapy for head-and-neck cancers: a double blind, randomized study. Int J Radiat Oncol Biol Phys. 2006;65(3):745-50.

21. Herrstedt J. Prevention and management of mucositis in patients with cancer Int J Antimicrob Agents. 2000;16(2):161-3

22. Lapeyre M, Charra-Brunaud C, Kaminsky MC. Management of mucositis following radiotherapy for head and neck cancers. Cancer Radiother. 2001; 5:121-30.

23. Du J, Cullen JJ, Buettner GR. Ascorbic acid: chemistry, biology and the treatment of cancer. Biochim Biophys Acta. 2012;1826(2):443-57.

24. Yeom CH, Jung GC, Song KJ. Changes of terminal cancer patients' healthrelated quality of life after high dose vitamin $\mathrm{C}$ administration. J Korean Med Sci. 2007;22(1):7-11.

25. Cameron E, Campbell A. The orthomolecular treatment of cancer. II. Clinical trial of high-dose ascorbic acid supplements in advanced human cancer. Chem Biol Interact. 1974;9(4):285-315

26. Jacobs $\mathrm{C}$, Hutton $\mathrm{B}, \mathrm{Ng} \mathrm{T}$, Shorr $\mathrm{R}$, Clemons $\mathrm{M}$. Is there a role for oral or intravenous ascorbate (vitamin $\mathrm{C}$ ) in treating patients with cancer? A systematic review. Oncologist. 2015;20(2):210-23.

27. Creagan ET, Moertel CG, O'Fallon JR, Schutt AJ, O'Connell MJ, Rubin J, et al. Failure of high-dose vitamin C (ascorbic acid) therapy to benefit patients with advanced cancer. A controlled trial. N Engl J Med. 1979;301(13):687-90.

28. Moertel CG, Fleming TR, Creagan ET, Rubin J, O'Connell MJ, Ames MM. High-dose vitamin $C$ versus placebo in the treatment of patients with advanced cancer who have had no prior chemotherapy. A randomized double-blind comparison. N Engl J Med. 1985;312(3):137-41.

29. Goel SAS, Mandal A, Singhal K. Emerging role of ascorbic acid in the management of advanced breast carcinoma as a chemosensitizer. Asian $\mathrm{J}$ Surg. 1999;22:333-6.

30. Berenson JR, Yellin O, Woytowitz D. Bortezomib, ascorbic acid and melphalan (BAM) therapy for patients with newly diagnosed multiple myeloma: An effective and well-tolerated frontline regimen. Eur J Haematol. 2009;82(6):433-9.

31. Harris HR, Bergkvist L, Wolk A. Vitamin C intake and breast cancer mortality in a cohort of Swedish women. Br J Cancer. 2013;109(1):257-64.

32. Itoh H, Ikeda S, Oohata Y. Treatment of desmoid tumors in Gardner's syndrome. Report of a case. Dis Colon Rectum. 1988;31:459-61.

33. Cole WC, Prasad KN. Contrasting effects of vitamins as modulators of apoptosis in cancer cells and normal cells: a review. Nutr Cancer. 1997;29(2):97-103.

34. WHO. Handbook for Reporting Results of Cancer Treatment. 1979. Geneva: WHO, pp. 1979;15-22

35. Cameron E, Pauling L, Leibovitz B. Ascorbic acid and cancer: a review. Cancer Res. 1979;39(3):663-81.

\section{SUMMARY}

The present trial had shown that oral vitamin C supplementation, particularly when consumed at high concentration i.e. $4 \mathrm{gm} /$ day can significantly decrease in intensity of mucositis in patients who suffer from oropharyngeal cancers and are under radiotherapy and CRT. No further side-effects were reported and the administered drug was proved easy and safe to use. 


\section{About Authors}

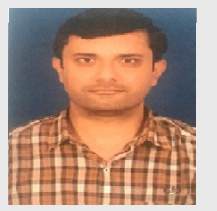

Dr Nallan CSK Chaitanya is presently pursuing PhD as an external scholar in Saveetha University, Chennai. His areas of interest include Oral Mucositis during cancer treatment, diagnosis and medical management of the same using conventional and alternative therapeutic modalities.

Cite this article: : Chaitanya NC, Muthukrishnan A, Rao KP, Priyanka DR, Ujwala P, Abhijeeth H, Kumar AN, Kovur A. Oral Mucositis Severity Assessment by Supplementation of High Dose Ascorbic Acid During Chemo and/or Radiotherapy of Oro-Pharyngeal Cancers - A Pilot Project. Indian J of Pharmaceutical Education and Research. 2018;52(3):532-9. 